\title{
PREFRONTAL LEUCOTOMY AND THE ANTICIPATION OF PAIN
}

\author{
BY
}

\author{
ALICK ELITHORN, MALCOLM F. PIERCY, and MARGARET A. CROSSKEY \\ From the Neurological Research Unit and the Department of Psychology, \\ the National Hospital, Queen Square, London
}

Preliminary observations (Elithorn, Piercy, and Crosskey, $1954 \mathrm{a}$ and $\mathrm{b}$ ) on patients undergoing prefrontal leucotomy revealed changes in autonomic function following the operation, and it was suggested that these were largely due to a reduction in the abnormal autonomic activity which accompanied the pre-operative mental disturbance. Similar views have been expressed by other workers (Carscallen, Buck, and Hobbs, 1951 ; Conklin, 1951). Solomon and Greenblatt (1953) also report that patients improved by leucotomy showed a physiological improvement in their blood-pressure responses to intravenous mecholyl. They appear, however, to regard the physiological changes as causative rather than as secondary to psychological improvement.

Since our own observations and those of others suggested that the frontal areas damaged by leucotomy contained no primary vegetative centres an attempt was made to devise a test which would measure autonomic changes which could be interpreted in terms of the psychological effects of leucotomy. A typical effect of a prefrontal destructive lesion, whether therapeutic or accidental, is an apparent reduction in the patient's feelings of anxiety. Further, an early paradoxical observation was that patients who suffered from severe pain, organic in origin, might be relieved of their suffering although their perception of pain remained unimpaired (Chapman, Rose, and Solomon, 1948). With a view therefore to analysing further the changed attitude to pain which follows prefrontal leucotomy the following test procedure was devised.

\section{Methods}

Autonomic reaction was measured in terms of the change in the electrical resistance of the palmar skin accompanying alteration in the rate of sweating (psychogalvanic reflex). Responses were measured to two stimuli : an electrical stimulus and a red light which was regularly exhibited for a short interval 7 seconds before the start of the electrical stimulus. Successive electrical stimuli were increased in intensity in steps of 2.5 volts from a subliminal value to the maximum intensity which the subject was prepared to tolerate. Measurements were also taken of the resting level of skin resistance, responses to maximal inspirations and to a sudden loud noise, the smallest perceptible electrical stimulus, and the maximum stimulus tolerated. At the end of the experiment responses to the red light were measured after the subject had been told that there would be no further electrical stimuli.

The size of the psychogalvanic reflex depends? not only on the immediate stimulus but also on such factors as the time of day, the season, environ- $\frac{\odot}{\circ}$ mental temperature, mood, and the presence oro absence of psychiatric disease (Richter, $1929 ; 0 \mathbb{8}$ Conklin, 1951). Our observations were made at $\varnothing$ the temperature prevailing in the laboratory을 Consequently, no emphasis is placed on the absolute values of the observed responses. However, overall? changes in autonomic reactivity would not be expected to have much effect on the proportional relationship between the responses to two different stimuli unless the significance of one stimulus changed in relation to the other. Accordingly we studied the ratio of the response following the electrical stimulus to the response following the warning red light.

\section{Procedure}

The apparatus used for recording the psychogalvanic responses and for administering the electrical stimuli has been described elsewhere (Elithorn and others, 1954a). Fig. 1 shows sample records.

Each test session lasted about 50 minutes and was divided into three roughly equal parts. Before each part the procedure was explained to the patient who was comfortably seated throughout with the arms supported on rests.

During part one the subject rested quietly while the electrodes were applied and then measurements were made of the resting skin temperature and skin 
(a) Pre-operative

(b) Post-operative

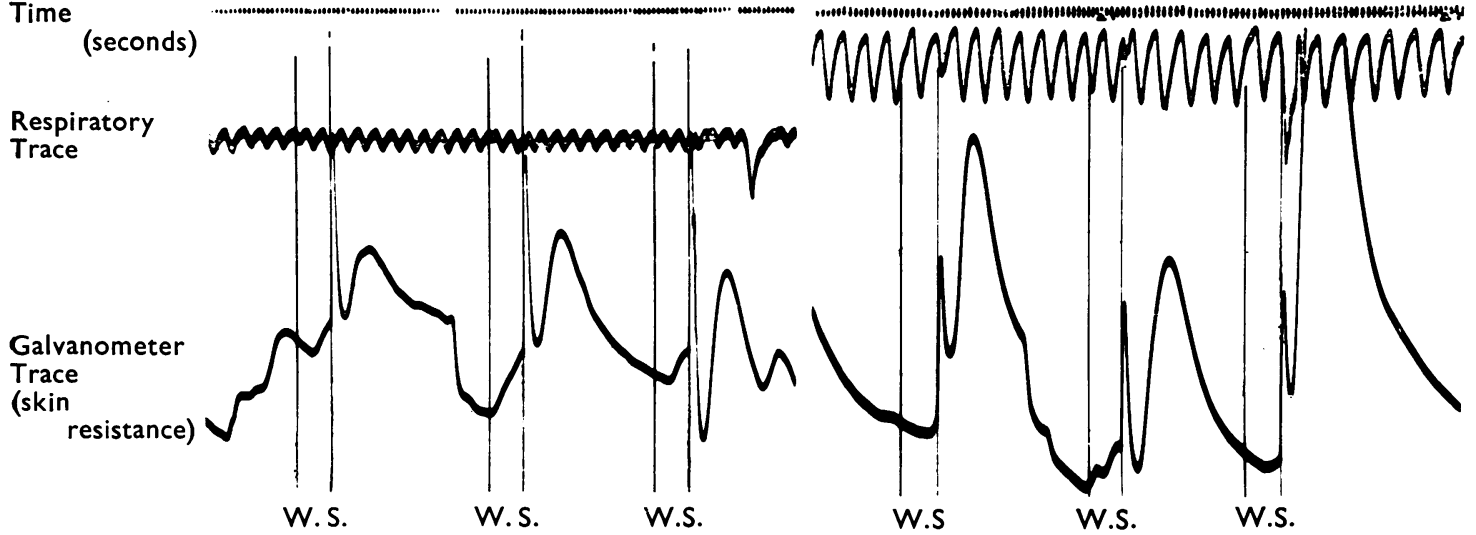

Fig. 1.-Sample records obtained with subject C. G. (a) six days before and (b) 236 days after a modified leucotomy. An upward deflection of the galvanometer trace corresponds to a fall in skin resistance. A rise of $1 \mathrm{~cm}$. is equivalent in (a) to a fall of $2.0 \times 10^{3} \mathrm{ohms}$ and in (b) to a fall of $2.3 \times 10^{3} \mathrm{ohms}$. The vertical lines mark the time of presentation of the warning light (W) and of the shocks (S). In both records the stimuli shown are the three occurring immediately before the subject said "Stop". The disturbance in the galvanic trace during the exhibition of the shock is due to stimuli escape.

resistance. A short recording was then made of the spontaneous changes in skin resistance which took place while the subject was resting and after this the responses to three maximal inspirations and a sudden noise were recorded. The resting skin resistance and skin temperature were then measured again. In part two the subject's sensations were tested : first, on each hand, the strength of shock which he could just detect was measured (the shocks lasted for 400 milliseconds and each consisted of a series of square pulses with a duration of 70 milliseconds and a frequency of 100 a second). He was then told that the shock on the right hand was going to be increased gradually until it became painful. The subject was instructed to say "Stop" when it became as painful as he could bear and he was assured that as soon as he said this the shock would be turned off. It was pointed out that the shock would cause no damage and that it would stop as soon as he said "Stop". Apprehensive patients were encouraged to do their best ; stoics and others were instructed not to martyr themselves but to say "Stop" when the pain was more than they could reasonably bear. Following these instructions the shock was reapplied to the right hand and was increased in strength in units of 2.5 volts each second until the subject said "Stop". This was repeated twice with the interval between shocks increased to approximately five seconds and then once again with shocks every second (with both time intervals the shock duration as for the perception test was approximately 400 milliseconds).

The strength of shock which the subject was receiving when he said "Stop" was recorded as the refusal level and the ratio of this to the perceptual level was designated the "pain tolerance ratio". When the four estimates of the pain tolerance ratio had been obtained, the subject was told to rest and part three of the test was explained. In part three a final series of shocks was exhibited. Each shock was of the same character and duration as before and each was $2.5 \mathrm{v}$. stronger than its predecessor. The strength of the first shock was, however, so chosen that approximately the first three stimuli would be below the subject's observed threshold of perception. The shocks were separated by an interval which was never less than 15 seconds and rarely more than 40 . Further, seven seconds before each shock a red warning light was exhibited, the significance of which was explained clearly to the subject, who was told to say " Red" whenever he saw the red light, "Right" whenever he felt the shock in his right hand, and "Stop" when the shocks became too strong. When the shock series had been brought to an end by the subject saying "Stop" he was told that there would be no more shocks, that we had nearly finished and that he would be shown a few more red lights, to which he must respond "Red" but that these would not be followed by a shock. Throughout the light shock series the psychogalvanic responses to each stimulus were recorded from the left hand (sample records are given in Fig. 1). At the end of the series resting-levels of skin resistance and skin temperature were again recorded. The effects of leucotomy on resting skin resistance and resting skin temperature have been reported elsewhere (Elithorn and others, 1954b) and call for no further 
comment. Preliminary experiments had shown that many subjects, and in particular psychiatric patients, had difficulty in determining a point at which the shock stimulus became painful. The point at which the stimulus became " too painful" was much more consistently judged and some preliminary experiments reported elsewhere (Elithorn and others, 1950) gave a test-retest correlation coefficient of $0.89(\mathrm{p}<0.001)$ for the pain tolerance ratio. The results obtained also seemed to bear a reasonable relationship to the clinical evaluation of the patient's attitude to pain (Table I). The pain tolerance ratios reported here are derived from the mean perception threshold for the right hand and the mean of the two refusal levels for the right hand observed when the shock was repeated once a second. The expectancy situation-part three-was designed to test the hypothesis that after leucotomy there would be a disruption of the relationship between the autonomic disturbance caused by the anticipation of pain and that caused by the pain itself. The procedure was not designed to test the formation of a conditioned reflex, but since the test shows some similarities to conditioning procedures, it was decided to show the subjects a few identical lights at the end of the expectancy run to make sure that conditioning had not occurred.

\section{Subjects}

Brief clinical details of the patients investigated are given in Table I. Fuller clinical summaries

TABLE I

CLINICAL SUMMARIES OF PATIENTS INVESTIGATED

\begin{tabular}{|c|c|c|c|c|c|c|c|c|c|c|c|c|}
\hline \multirow{2}{*}{$\begin{array}{l}\text { Sub- } \\
\text { ject }\end{array}$} & \multirow{2}{*}{$\begin{array}{l}\text { Hos- } \\
\text { pital } \\
\text { No. }\end{array}$} & \multirow{2}{*}{ Sex } & \multirow{2}{*}{ Age } & \multirow{2}{*}{ Diagnosis } & \multirow{2}{*}{$\begin{array}{l}\text { Type of } \\
\text { Operation }\end{array}$} & \multirow{2}{*}{$\begin{array}{l}\text { Effect of } \\
\text { Operation on } \\
\text { Psychiatric } \\
\text { State }\end{array}$} & \multicolumn{2}{|c|}{$\begin{array}{l}\text { Pain } \\
\text { Tolerance } \\
\text { (threshold } \\
\text { units) }\end{array}$} & \multicolumn{3}{|c|}{$\begin{array}{l}\text { Expectancy } \\
\text { (Shock-light) } \\
\text { Ratio }\end{array}$} & \multirow{2}{*}{$\begin{array}{c}\text { Time of } \\
\text { Final } \\
\text { Session } \\
\text { in } \\
\text { Months } \\
\text { after } \\
\text { Opera- } \\
\text { tion } \\
\text { (13) }\end{array}$} \\
\hline & & & & & & & $\begin{array}{c}\text { Mean } \\
\text { Value } \\
\text { Pre- } \\
\text { op. } \\
(8)\end{array}$ & $\begin{array}{c}\text { Mean } \\
\text { Value } \\
\text { Post- } \\
\text { op. } \\
(9)\end{array}$ & $\begin{array}{c}\text { Mean } \\
\text { Value } \\
\text { Pre- } \\
\text { op. } \\
\text { (10) }\end{array}$ & $\begin{array}{c}\text { Mean } \\
\text { Value } \\
\text { Post- } \\
\text { op. } \\
\text { (11) }\end{array}$ & $\begin{array}{c}\text { Obser- } \\
\text { ved at } \\
\text { Final } \\
\text { Ses- } \\
\text { sion } \\
(12)\end{array}$ & \\
\hline A.K. & 23166 & $\mathbf{M}$ & 48 & $\begin{array}{l}\text { Paranoid involutional depres- } \\
\text { sion }\end{array}$ & $\begin{array}{l}\text { Standard leu- } \\
\text { cotomy }\end{array}$ & Recovered & $7 \cdot 4$ & $6 \cdot 6$ & $4 \cdot 9$ & $10 \cdot 8$ & $6 \cdot 5$ & 5 \\
\hline A.C. & 19179 & $\mathbf{M}$ & 50 & $\begin{array}{l}\text { Cystic lung with hypochon- } \\
\text { driasis, thoracoplasty pain in } \\
\text { the chest, and hysteria }\end{array}$ & $\begin{array}{l}\text { Standard leu- } \\
\text { cotomy }\end{array}$ & Improved & $2 \cdot 2$ & $2 \cdot 1$ & $2 \cdot 7$ & $10 \cdot 0$ & $23 \cdot 5$ & 5 \\
\hline C.G. & 25458 & $\mathbf{F}$ & 50 & Paraphrenia & $\begin{array}{l}\text { Standard leu- } \\
\text { cotomy }\end{array}$ & Much improved & $4 \cdot 2$ & $4 \cdot 2$ & $2 \cdot 2$ & $3 \cdot 5$ & $7 \cdot 0$ & 9 \\
\hline A.M. & 14765 & $\mathbf{M}$ & 56 & $\begin{array}{l}\text { Cerebral arteriosclerosis, invo- } \\
\text { lutional depression }\end{array}$ & $\begin{array}{l}\text { Standard leu- } \\
\text { cotomy }\end{array}$ & Much improved & $3 \cdot 7$ & $2 \cdot 5$ & 13.4 & $28 \cdot 0$ & $19 \cdot 2$ & 13 \\
\hline J.P. & 8143 & $\mathbf{M}$ & 41 & $\begin{array}{l}\text { Post-encephalitic dystonia with } \\
\text { pain, depression, and hysteria }\end{array}$ & $\begin{array}{l}\text { Standard leu- } \\
\text { cotomy }\end{array}$ & Much improved & $1 \cdot 7$ & $1 \cdot 5$ & - & - & 一 & 一 \\
\hline E.S. & 18957 & $\mathbf{F}$ & 53 & $\begin{array}{l}\text { Post-herpetic neuralgia, reac- } \\
\text { tive depression }\end{array}$ & $\begin{array}{l}\text { Unilateral leu- } \\
\text { cotomy }\end{array}$ & 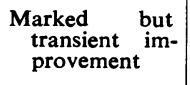 & $4 \cdot 7$ & $4 \cdot 5$ & $1 \cdot 7$ & $5 \cdot 2$ & $4 \cdot 3$ & 18 \\
\hline L.B. & 29566 & $\mathbf{F}$ & 44 & $\begin{array}{l}\text { Disseminated sclerosis with } \\
\text { severe central pain }\end{array}$ & $\begin{array}{l}\text { Unilateral leu- } \\
\text { cotomy }\end{array}$ & $\begin{array}{l}\text { Marked but } \\
\text { transient im- } \\
\text { provement }\end{array}$ & $2 \cdot 1$ & $3 \cdot 5$ & 3.4 & $4 \cdot 2$ & $4 \cdot 9$ & 3 \\
\hline H.W. & 25598 & $\mathbf{M}$ & 56 & $\begin{array}{l}\text { Post-herpetic neuralgia, depres- } \\
\text { sion }\end{array}$ & $\begin{array}{l}\text { Rostral leuco- } \\
\text { tomy (with } \\
\text { secondary } \\
\text { thrombosis) }\end{array}$ & $\begin{array}{l}\text { Very much im- } \\
\text { proved }\end{array}$ & $3 \cdot 2$ & $3 \cdot 8$ & $4 \cdot 2$ & $38 \cdot 5$ & $6 \cdot 1$ & 11 \\
\hline J.H. & 28174 & $\mathbf{M}$ & 50 & $\begin{array}{l}\text { Tinnitus, endogenous depres- } \\
\text { sion }\end{array}$ & $\begin{array}{l}\text { Rostral leuco- } \\
\text { tomy }\end{array}$ & Much improved & $2 \cdot 5$ & $2 \cdot 9$ & $2 \cdot 9$ & $7 \cdot 5$ & $2 \cdot 7$ & 20 \\
\hline W.H. & 22074 & $\mathbf{F}$ & 37 & Chronic anxiety state & $\begin{array}{l}\text { Rostral leuco- } \\
\text { tomy }\end{array}$ & Improved & $7 \cdot 3$ & $7 \cdot 1$ & $4 \cdot 7$ & $11 \cdot 5$ & $11 \cdot 7$ & 13 \\
\hline A.S. & 11773 & $\mathbf{M}$ & 46 & $\begin{array}{l}\text { Obsessional neurosis, chronic } \\
\text { anxiety state }\end{array}$ & $\begin{array}{l}\text { Rostral leuco- } \\
\text { tomy }\end{array}$ & Much improved & 一 & - & $2 \cdot 3$ & $4 \cdot 9$ & $3 \cdot 3$ & 7 \\
\hline G.P. & 25908 & $\mathbf{M}$ & 65 & $\begin{array}{l}\text { Chronic anxiety state, involu- } \\
\text { tional hypochondriasis }\end{array}$ & $\begin{array}{l}\text { Lower segment } \\
\text { leucotomy }\end{array}$ & $\underset{\text { provement }}{\text { Transient }}$ & $2 \cdot 5$ & $2 \cdot 4$ & $5 \cdot 0$ & $14 \cdot 1$ & 1.9 & 4 \\
\hline M.D. & 16575 & $\mathbf{M}$ & 41 & Hypochondriasis & Cingulectomy & Improved & $4 \cdot 1$ & $5 \cdot 1$ & $4 \cdot 9$ & $4 \cdot 2$ & $4 \cdot 4$ & 18 \\
\hline J.G. & 27508 & $\mathbf{M}$ & 43 & $\begin{array}{l}\text { Inadequate } \\
\text { chronic anxiety state, de- } \\
\text { pression }\end{array}$ & Cingulectomy & Much improved & $3 \cdot 8$ & $4 \cdot 5$ & $3 \cdot 7$ & $6 \cdot 0$ & $2 \cdot 1$ & 6 \\
\hline
\end{tabular}


will be published elsewhere. The only criterion of selection used was the availability of the patient for pre-operative testing.

\section{Results}

Pain Tolerance.-The mean pre-operative and mean post-operative values for the pain tolerance ratios are given in Table $I$. The effect of the operation on the toleration of this particular painful stimulus is very small. Following leucotomy, tolerance is increased in six subjects and reduced in six subjects. For subject C. G. the post-operative value was the same as that found pre-operatively. Subject A. S., who was obsessional and had a high skin resistance, always tolerated as strong a shock as we were able to provide. Consequently we have no data as to the effect of leucotomy on his pain tolerance. Fig. 2, in which the pre-operative and post-operative pain tolerance ratios are plotted

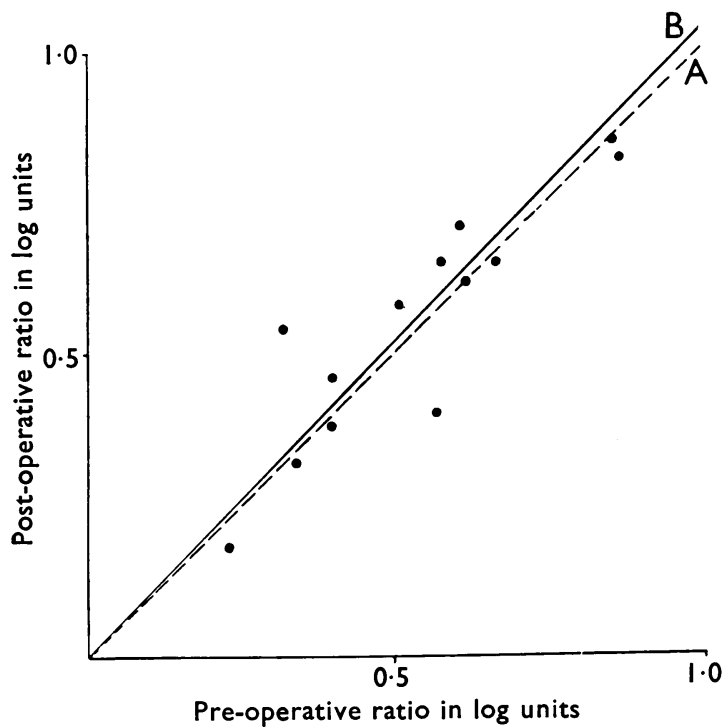

FIG. 2.-The observed relationships between the post-operative pain tolerance ratio and that found pre-operatively is represented by the line $B$ which has the form $\log y=1.03 \log x$. This is not significantly different from line $A$ which represents no change.

in logarithmic units, presents these findings graphically. In Fig. 2 the line $A$ is that on which hypothetical observations would fall if the ratios found post-operatively were the same for each subject as those found pre-operatively. The observed values do, in fact, lie about this line, the mean observed relationship between the pre-operative and post-operative findings being represented by the line B. Student's " $t$ " test (Fisher, 1942), using these logarithmic values, shows that the post- operative ratios are not significantly different from those found pre-operatively $(\mathrm{t}=0.55 \mathrm{n}=12$, $\mathrm{p}>0.5$ ). It is clear, therefore, that this ratio is a repeatable observation measuring a pain tolerance which is different in different subjects and which is not significantly changed when the test is repeated after a full or modified leucotomy.

Autonomic Responses.-Day-to-day variations in the psychogalvanic responses resulting from environmental conditions were large, relative to any overall effect due to the operation. Indeed, as previously reported (Elithorn and others, 1954b), the operation appeared to affect the overall responsiveness in opposite directions in different patients. For the group as a whole the post-operative responses to both the light and the shock tended to be lower than those found pre-operatively, but this change was not significant. However, as we have argued, much of this day-to-day variation is excluded if we consider the relationship between the responses to the shocks and the responses to the warning lights rather than their absolute values. This relationship can be conveniently expressed by the ratio of the mean shock response to the mean light response. We may call this the "expectancy ratio". This statistic has been calculated for each patient on each test session. In Table $I$ the mean values preoperatively and post-operatively are presented (columns 10 and 11) together with the value found on the last occasion on which each patient was tested (column 12). The time between operation and the final examination is also given (column 13). It will be seen that post-operatively the mean ratio was increased in 12 out of 13 subjects. Further, in nine patients this increase was present at least three months after operation. For these nine patients the mean follow-up time was nine months. It is worth noting that this group contains all those patients who had a standard leucotomy on at least one side. Neither of the two patients subjected to cingulectomy showed a persisting change, and one of these (M. D.), who was studied fairly thoroughly (three sessions pre-operatively and five post-operatively), was the only subject who showed no post-operative rise in the expectancy ratio.

In Fig. 3 these results are shown graphically. The presentation is the same as that adopted for the pain tolerance ratios in Fig. 2. The line $A^{\prime}$ is again that about which the observations would lie if the post-operative findings did not differ significantly from those found pre-operatively. In fact, the post-operative ratios (with one exception) are all higher than those found pre-operatively. 
In Fig. 3 the mean relationship between the postoperative and the pre-operative expectancy ratios is expressed by the line $B^{\prime}$ which has the form

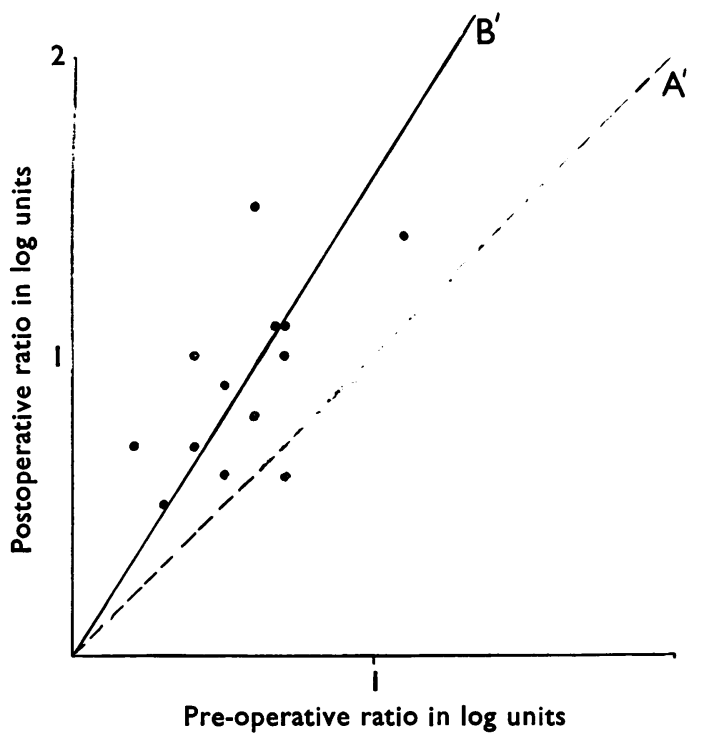

Fig. 3.-The observed relationship between the post-operative expectancy ratio and that found pre-operatively is represented by the line $\mathrm{B}^{\prime}$ which has the form $\log y=1.5 \log x$. This is significantly different $(p<0.001)$ from line $A^{\prime}$ which represents no change.

$\log y=1.5 \log x$. Student's " $t$ " test shows that this effect is highly significant $(t=5.40$ $n=12, \mathrm{p}<0.001$ ).

It can be shown that this effect is related to the operation and is not merely the result of repetition of the test since the effect is in the opposite direction to the observed effect of practice. Ten of these 13 patients were tested more than once pre-operatively and eight showed on retesting a fall in the expectancy ratio. In one subject (A. K.) there was a rise in the ratio between the first and second and between the second and third pre-operative sessions, and the remaining patient (J. H.) showed a fall followed by a rise. These two patients both had an endogenous depressive element to their illnesses. Thus the results obtained with these patients clearly show that after leucotomy there is a reduction in the autonomic disturbance (" reflex sweating ") which follows the threat of a painful stimulus as compared with the autonomic disturbance which follows the painful stimulus itself. This result cannot be explained as a practice or acclimatization effect and is not due to any alteration in the perception of, or toleration of, avoidable pain.
Individual Results.-As explained above, the effect of repeating the situation was to produce a reduction in the expectancy ratio. This effect was the opposite to the effect of leucotomy and so may partly mask the effect of the operation. Indeed, this tendency for the light response to increase with repetition of the test was so marked that repeated testing in the immediate post-operative period reduced the expectancy ratio of seven subjects to a value less than that found at the first pre-operative session. This increase in the relative response to the light signal was observed in all subjects who were tested repeatedly at short intervals and occurred even when the patient was euphoric and clearly undisturbed by the light signal. This excessive " recovery" of responsiveness to the light signal disappeared after the patient's discharge from hospital when intervals between tests increased. This observation provides additional evidence for the association of the increment in response to light with frequency of testing.

The following protocol for one patient illustrates a typical sequence of events. This patient has been chosen partly because clinically he had a successfub leucotomy which altered his reaction to his own neuralgic pains, partly because the operation produced a mild but typically frontal type of personality change without definite intellectual loss, and partly because our own data are particularly complete.

Patient H. W. (Hospital No. 25598), was a married man aged 56, a painter and decorator by trade. The diagnosis was post-herpetic neuralgia and reactive depression. His main complaint was of terrible pain in the chest and back following an attack of shingles 18 months before. There was no family history of nervous or mental disease.

As a child he suffered from frequent minor ailments and had always been hypochondriacal. He has been described as meticulous, dogged and of rather restricted interests. At work he was inclined to shirk unless given a specific job to do in which case he worked well. His wife, who was said to be repeatedly unfaithful, left him and he made a somewhat histrionic attempt at suicide. He has since had no inclination to remarry.

He had suffered from urinary stone, and at the age of 28 had a chest cold which left him with a pain which has persisted ever since. In 1941 he was discharged from the army with a diagnosis of psychoneurosis. Two years later he had an illness which was characterized by nervousness, tremulousness, and a fear of heights. For the five years preceding his present illness he had remained well.

In May, 1949, he had an attack of shingles in the region of the intercostal spaces D.6-9 and this left him with pain in the left chest, which had been present ever since; it varied in severity but nothing relieved 
it. After six months he managed to return to work but six months later he again had to give up and had not worked since. In addition to the pain he was tremulous and felt generally frightened and stated that he had lost all grip on himself. His appetite was poor, he lost weight, and he became depressed and somewhat tearful. He had palpitations, sweated easily, and had fears of dogs, traffic, and cancer. On examination he did not seem to be grossly depressed and stated that while in hospital his pain did not really worry him, although it was constantly present, as a dull ache. Outside he found the pain distracting when he had to do anything. There was no evidence of any intellectual deterioration. His blood pressure was $246 / 130 \mathrm{~mm}$. $\mathrm{Hg}$. On November 8, 1950, bilateral blind rostral leucotomy was performed.

Two days after the operation the patient was found to be somewhat confused, disorientated, and drowsy. There were no neurological signs. It was thought that he had had a secondary haemorrhage or thrombosis but he rapidly improved and subsequently made a good recovery. Incontinence occurred only in the first postoperative month. Although he still complained occasionally of pain he seemed little distressed and was much more cheerful in mood. He showed some definite post-operative apathy and was mildly irritable when harried.

He returned to live with the family with whom he had lodged for 20 years. At first they noted that he was much quieter, took less interest in the family, and had difficulty in getting up early in the morning. There was also an exacerbation of his usual sarcasm. He never spontaneously complained of pain. Two and a half years after the operation his landlady reported that he was a picture of health, never complained of pain, and did not appear to be anxious or depressed. He worked well and had regained his old interests but was still rather more selfish and irritable than pre-operatively. The patient was very glad that he had had the operation, and said that it had reduced the pain which nevertheless was still with him in the evenings. He was no longer tremulous, did not suffer from palpitations, and had lost his fear of cancer and traffic although he was still nervous of dogs. He expressed himself as still mildly depressed but nevertheless looked cheerful. His manner was somewhat dull and lifeless but he was able to give a reasonable summary of current events, which showed an interest and a grasp that were above average for his occupation.

\section{Psychological Tests}

Pre-operative psychological tests showed an I.Q. of 120. Two years post-operatively his I.Q. on the same tests was 125 and analysis of the scores on sub-tests suggested only minimal intellectual loss.

Table II gives the summarized data for each of the 10 occasions on which this patient was tested. Figs. 4a-d show graphically the individual responses on four of these occasions ; (a) immediately preoperatively, (b) immediately post-operatively (20 days), (c) immediately before discharge from hospital (58 days post-operatively), and (d) on the last follow-up examination (343 days post-operatively). In these histograms the sizes of the paired responses to the light and to the shock are represented by the height of the blocked and hatched columns respectively. Fig. $4 \mathrm{a}$ is typical of the results obtained pre-operatively with anxious subjects. The responses to the light are relatively large but

TABLE II

RESPONSES OF H. W. TO PSYCHOLOGICAL TESTS

\begin{tabular}{|c|c|c|c|c|c|c|c|c|c|c|c|}
\hline $\begin{array}{c}\text { Session } \\
\text { Number }\end{array}$ & $\begin{array}{c}\text { Time in } \\
\text { Days } \\
\text { before } \\
\text { and after } \\
\text { Operation } \\
\text { (2) }\end{array}$ & $\begin{array}{c}\text { Time } \\
\text { since } \\
\text { Previous } \\
\text { Test in } \\
\text { Days } \\
\text { (3) }\end{array}$ & 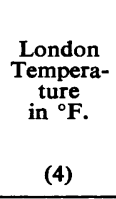 & 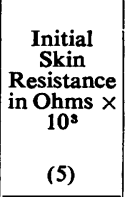 & 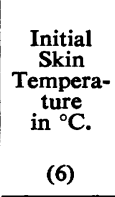 & $\begin{array}{c}\begin{array}{c}\text { Pain } \\
\text { Tolerance } \\
\text { Ratio }\end{array} \\
\text { (7) }\end{array}$ & $\begin{array}{c}\text { Mean } \\
\text { Response } \\
\text { to } \\
\text { Warning } \\
\text { Light in } \\
\text { Ohms } \times \\
10^{3} \\
\text { (8) }\end{array}$ & $\begin{array}{c}\text { Mean } \\
\text { Response } \\
\text { to } \\
\text { Shock } \\
\text { Stimulus } \\
\text { in Ohms } \\
\times 10^{3} \\
\text { (9) }\end{array}$ & $\begin{array}{c}\begin{array}{c}\text { No. of } \\
\text { Stimulus } \\
\text { (N) }\end{array} \\
\text { (10) }\end{array}$ & $\begin{array}{c}\text { Shock/ } \\
\text { Light } \\
\text { Ratio }\end{array}$ & $\begin{array}{c}\text { Mean } \\
\begin{array}{c}\text { Final } \\
\text { Light } \\
\text { Response } \\
(\mathbf{N}=4)\end{array} \\
(12)\end{array}$ \\
\hline 1 & -5 & - & 49.0 & 89 & $23 \cdot 2$ & $3 \cdot 7$ & 0.56 & 2.62 & 19 & $4 \cdot 7$ & 0.03 \\
\hline 2 & -1 & 4 & $48 \cdot 2$ & 161 & $24 \cdot 6$ & $2 \cdot 7$ & 1.72 & $6 \cdot 27$ & 23 & 3.7 & 0.03 \\
\hline$\underset{3}{\text { Bilateral } r}$ & $\begin{array}{l}\text { ostral leucot } \\
\quad+20\end{array}$ & ${ }^{m y} 21$ & $57 \cdot 0$ & 253 & $23 \cdot 1$ & $(>2.8)$ & 0.22 & $11 \cdot 28$ & 31 & $52 \cdot 2$ & 0.04 \\
\hline 4 & +30 & 10 & $45 \cdot 2$ & 195 & $31 \cdot 0$ & $4 \cdot 0$ & $1 \cdot 12$ & 15.49 & 24 & $13 \cdot 8$ & 0.00 \\
\hline 5 & +42 & 12 & $37 \cdot 7$ & 167 & $26 \cdot 2$ & 3.8 & 1.54 & $5 \cdot 30$ & 21 & 3.5 & 1.9 \\
\hline 6 & +58 & 16 & $51 \cdot 2$ & 144 & 33.0 & $3 \cdot 5$ & 4.04 & $7 \cdot 85$ & 25 & 1.9 & 0.90 \\
\hline 7 & +154 & 96 & $47 \cdot 4$ & 230 & $26 \cdot 3$ & $4 \cdot 4$ & 0.34 & 5.74 & 28 & 16.9 & 0.00 \\
\hline 8 & +210 & 56 & $69 \cdot 8$ & 270 & $36 \cdot 7$ & $3 \cdot 3$ & 0.17 & $6 \cdot 21$ & 23 & $37 \cdot 6$ & 0.08 \\
\hline 9 & +287 & 77 & 64.0 & 292 & $35 \cdot 4$ & $3 \cdot 7$ & 0.04 & $6 \cdot 39$ & 25 & $145 \cdot 3$ & 0.00 \\
\hline 10 & +343 & 57 & 56.8 & 294 & $31 \cdot 5$ & $(>4 \cdot 1)$ & 0.36 & 7.06 & 29 & 19.7 & 0.00 \\
\hline
\end{tabular}


the size of the light response, and even the size of the shock response, does not appear to depend

Response to warning light

Response to shock

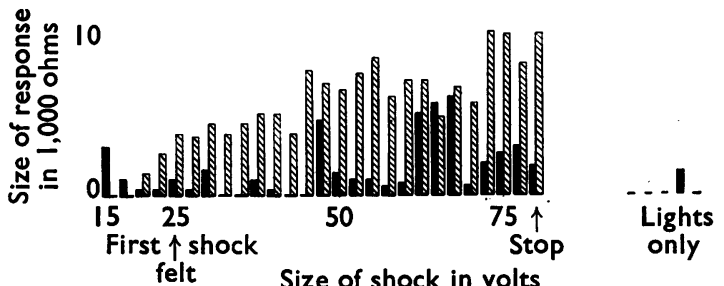

FIG. 4a.-Responses to warning lights and shocks in subject $\mathbf{H}$. W. one day pre-operatively.

very closely on the strength of the shock. This record also demonstrates clearly that this test cannot be regarded simply as a conditioning situation because the response to the light disappears as soon as the subject is told that there will be no more shocks.

Fig. 4b shows the responses obtained three weeks later, 20 days after a successful modified leucotomy. The light responses have practically disappeared whilst the responses to the shocks are much increased. Two further points are worth noting : first that the shock response bears a much more direct relationship to the strength of the stimulus and secondly that, although there is a great reduction in the anticipatory response that accompanies the light, there is also a relatively marked failure to inhibit this response when the light no longer signals a subsequent shock. In Fig. 4c the responses to the light are large, but despite this, and despite the irregular size of the responses to the shock, the patient showed no
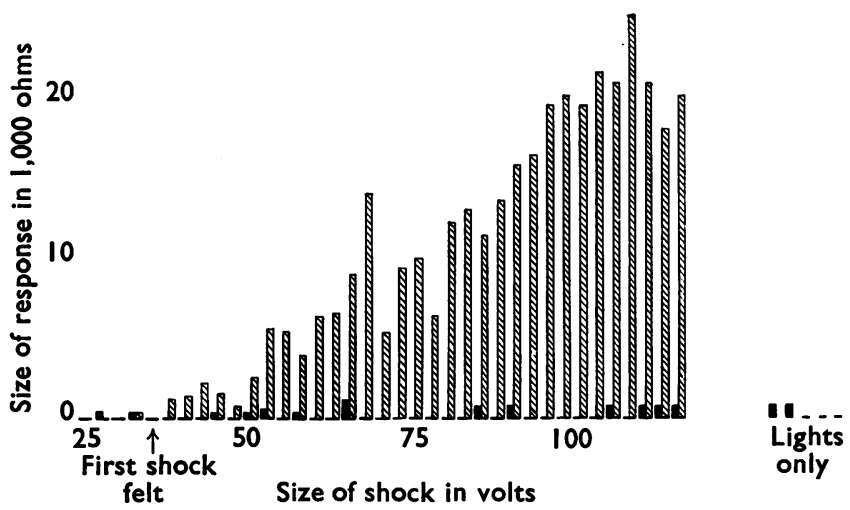

Fig. 4b.-Responses to warning lights and shocks in subject H. W. 20 days post-operatively. signs of anxiety and indeed was rather apathetic. The presence of relatively large responses to the exhibition of the light after the electrical stimuli had ceased suggests again that there may be some failure of inhibition and perhaps some conditioning. These points are discussed more fully below.

Fig. 4d shows the response obtained 11 months post-operatively; the responses to the light are almost absent although there is still considerable variation in the size of the shock responses. Two anomalous light responses call for explanation. First that which occurred immediately preceding

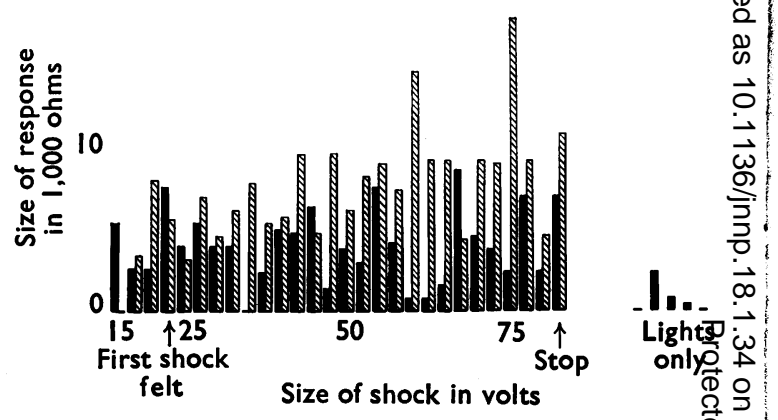

FIG. 4c.-Responses to warning lights and shocks in subject $\mathrm{H}$. 58 days post-operatively.

I Response to warning light

Response to shock

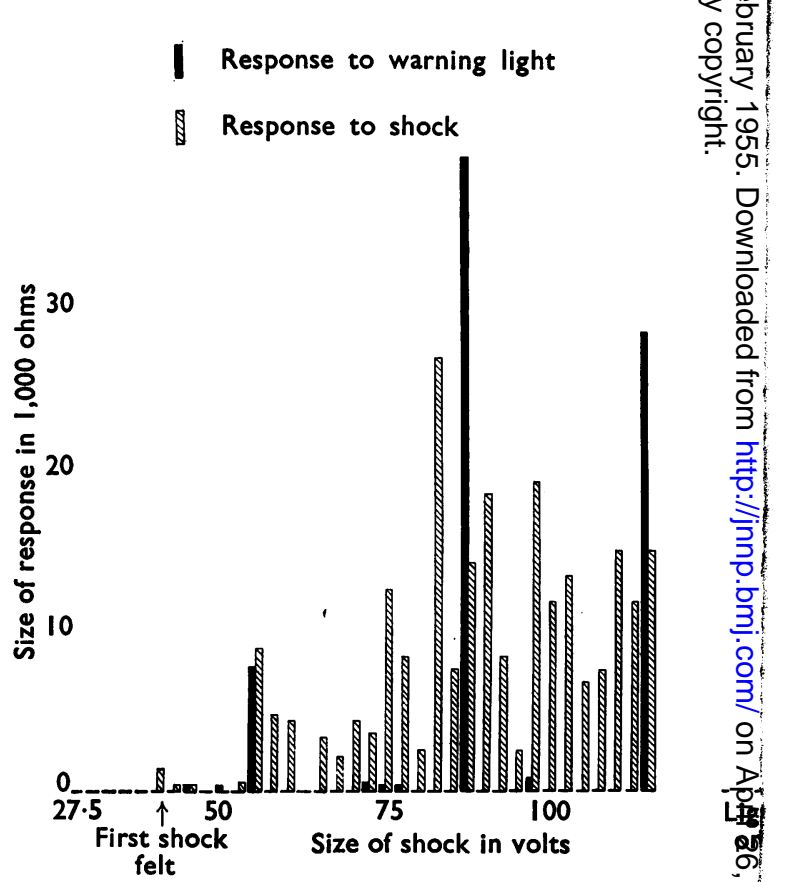

Fig. 4d.-Responses to warning lights and shocks in subject H. W. 34

FiG. 4d.-Responses to warning lights and shocks
post-operatively.

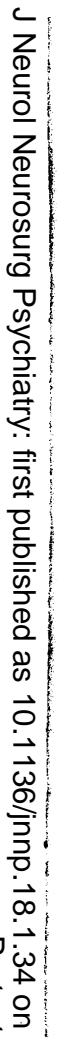


the $82.5 \mathrm{v}$. shock stimulus was closely associated with a large inspiratory sigh and the fall in skin resistance is clearly a physiological response to this respiratory excursion rather than a psychological response to the warning light. Secondly this was the last session on which this patient was to be tested and, since he showed virtually no response to the warning light, it was thought that it would be as well to show clearly that this was not due purely to an overall failure to respond to psychological stimuli. Accordingly, before the last electrical stimulus, he was shown a white light instead of a red one. This resulted in a large psychogalvanic resporise. This response and the response associated with the large inspiratory sigh show convincingly that the poverty of the responses to the red light was not due to an overall reduction in autonomic reactivity.

Table II shows the relationship of these changes in anticipatory responses both to the operation and to the frequency of test repetition.

\section{Discussion}

Several workers have reported the effect of various psychosurgical procedures on tise perception of pain. They have shown that there may be in individual cases a rise in pressure pain tolerance (Le Beau, 1950), no alteration in heat pain perception (Wolff, 1950 ; King and Clausen, 1952), a dezrease in heat pain perception (King, Clausen, and Scarff, 1950), and an increase in the withdrawal and wince response to painful thermal stimulation (Chapman and others, 1948). These changes in the perception of, and the response to, painful stimuli tend to disappear if the investigations are repeated after the immediate post-operative recovery period has passed (Chapman and others, 1950). These results are thus essentially in agreement with the present observations on the tolerance of a painful electrical stimulus. These show that while minor changes in pain tolerance occur they are insignificant in relation to the pre-operative variation and cannot account for the relief of suffering which leucotomy often produces. Further, the consistency of the pre- and post-operative pain tolerance ratios indicates that any changes found in the expectancy test cannot be due to variations in the amount of immediate pain tolerated post-operatively. Hardy, Wolff, and Goodell (1952) argue that the response to pain after leucotomy depends greatly on the intensity of the pain under consideration and point to clinical evidence that, although reaction to persistent mild pain is much reduced by the operation, nevertheless immediate reaction to pain of high intensity may be unchanged or increased.
This observation finds a parallel in our results in the unchanged or reduced tolerance ratios and the greater discrepancies post-operatively in autonomic reactivity to low and high intensities of eleztrical stimulation.

Previous investigators have come to contradictory conclusions concerning the effect of leucotomy on the anticipation of painful stimuli. Thus Ashby and Bassett (1950) concluded that the psychogalvanic responses to painful stimuli showed no major uniform change following leucotomy and noted in particular that the response to "threat" was unaltered. On the other hand Malmo and Shagass (1950) demonstrated that following leucotomy patients showed an increased response to painful stimuli in that they more frequently withdrew the head from painful stimuli and gave bigger psychogalvanic responses. Moreover they suggested that reduced anticipatory tension was indicated by the observation that their patients showed post-operatively fewer finger movements and fewer neck-muscle potentials in the rest periods between stimuli. Although they did not investigate the influence of acclimatization effects the results reported by Malmo and Shagass are essentially in agrezment with clinical observations and with our own findings.

The anomalous conclusions of Ashby and Bassett call for further discussion. These authors recorded the psychogalvanic responses to four unpleasant stimuli : (1) a pungent gas (NH), (2) a pinch on the ear, (3) a bright flash, and (4) a touch of cotton wool to the conjunctiva. Each stimulus was exhibited in "real" form and as a "threat" (e.g., the ammonia bottle was presented corked and uncorked). Their statistical analysis showed clearly that in different patients the operation produced opposite effects on overall reactivity-a result which agrees with the detailed data of the present experiment (not presented here) and with other observations which we have reported elsewhere (Elithorn and others, 1954b). Their analysis failed however to show any differential effect of the operation on the two types of stimulus. Re-examination of their data shows that, in conformity with our own results, five out of their six subjects showed post-operatively an increase in the ratio of the response to real stimulus/response to threat. That this failed to give a significant interaction in their analysis is probably due to the large overall variability of the responses and to the small number of patients examined. It must be pointed out also that the distinction between their two classes of stimuli is not great. The threat situation was an immediate one and contained little anticipatory 
element whilst the "real" stimuli were such as might lead patients to think themselves more frightened than hurt. It is clear therefore that Ashby and Bassett's observations are not in fact discordant with our own and are essentially in agreement with our hypothesis.

So far in this discussion it has been assumed that relatively large anticipatory responses to the warning light are indicative of excessive subjective anxiety and are roughly proportional to it. To a large extent this is probably true and a subsequent study in which the relative anticipatory responses of a group of patients havc been correlated with an independent psychiatric assessment of anxiety will be published at a later date. Malmo and Shagass have moreover already shown (Malmo and Shagass, 1949) that higher levels of muscle tension and more frequent " spontaneous" psychogalvanic responses are found during the resting phases between painful stimuli in anxious subjects than in normal controls. We have already said that conditioned reflex terminology cannot be strictly applied to responses to a stimulus towards which a conscious "set" can be adopted by the subject. Mowrer (1938) has taken a similar theoretical standpoint and also used the term " expectancy" to describe the set adopted by the subject in situations similar to ours. Nevertheless this theoretical position does not account for the post-operative observation that the expectancy ratio tended to fall with repetition of the test although the subject remained unanxious. A similar difficulty is provided by the tendency for the response to the warning light which occurs after the subject has been told that there will be no more shocks to be post-operatively comparatively greater than pre-operatively. It could be argued that the post-operative observations are closer than the pre-operative findings to what is observed in Pavlovian conditioning experiments. Certainly our test situation resembles those which lead to the development of "trace conditioning" in animal experiments.

In delay and trace conditioning there is a tendency for the conditioned response to be:ome delayed with training and to move up towards the unconditioned response (inhibition of delay). Our records are not on a large enough time scale to allow us to examine in detail the time relationships of individual responses, but it is clear that delayed responses to the warning light did occur particularly with frequent repetition of the test both before and after the operation. Fig. 1 shows such a delayed response.

It would seem reasonable therefore to postulate two components to the autonomic response to the warning light: (1) a response closely correlated with subjective apprehension, which is greater in habitually anxious patients ; and (2) a "conditioned" response which is determined by the previous association of the stimulus and is largely independent of subjective feelings of anxiety. This position would allow of a reduced correlation post-operatively between the expectancy ratio and subjective anxiety and would also make it easier to understand the post-operative tendency for responses to the light to occur after the subject has been told that no shock will follow. It might be that the relief of subjective anxiety after leucotomy releases comparatively simple conditioning mechanisms from control by autonomic regulating mechanisms involved in the physiological substrate of conscious anxiety. Such a release effect might involve changes in the balance of excitation and inhibition of autonomic responses.

We have argued elsewhere (Elithorn and others, $1954 \mathrm{a}, \mathrm{b})$ on independent evidence that similar damage to frontal tissue may in one subject lead to the reduction of abnormal excitation, and ino another to a decrease of pathological inhibition It is perhaps of interest therefore to point ouf $\frac{0}{2}$ that our present findings might be interpreted a $\vec{\Omega}$ providing evidence that leucotomy may reduce both excitation and inhibition in the same subjecto If the responses to the warning signal are partlio " anxious" in origin and partly due to independent. conditioning then the reduction in the response to요용 the light when the subject is told there will be no or further shocks presumably involves positive inhibition of the acquired tendency to respond to light. The immediate extinction of the responses to the light when this is no longer reinforced by the shock is very marked pre-operatively. This extinction is much reduced after leucotomy and this effect may well be due to a failure of the normal tendency to inhibit the acquired conditioned response to the light when the subject is told that no further shocks will occur. Further evidence of a reduction in inhibition post-operatively is an increase in the absolute size of the shock responses and their closer relationship to the strength of the stimulus. Post-operative decrease in excitation is of course illustrated by the comparatively smaller responses to lights when the subject is aware that they will be followed by a painful stimulus. All these effects can be seen in subject $H$. W.

\section{Summary}

In order to test the hypothesis that prefrontal leucotomy relieves painful conditions by reducing 
the anticipatory element of fear a pain-expectancy test was devised. The relative disturbance caused by a painful shock and by a preceding warning light was estimated by measuring the ratio of the psychogalvanic responses aroused by these two stimuli. Twelve of the 13 patients examined showed post-operatively an increase in this ratio which indicates a relative reduction in the autonomic disturbance caused by the warning signal. It was shown that this reduction in the anticipatory fear associated with a painful stimulus was not due to an alteration in the perception of pain or to a reduction in the amount of pain tolerated during the test.

One subject, who had been relieved by leucotomy of a totally incapacitating preoccupation with a post-herpetic neuralgia, is reported in detail.

We wish to thank the physicians and surgeons of the National Hospital who allowed us to examine the patients under their care. In particular we are grateful to Dr. E. A. Carmichael, Dr. Eliot Slater,- and Professor O. L. Zangwill for advice and help. To Dr. G. D. Dawson we are grateful for technical help and to Dr. P. Armitage of the M.R.C. Statistical Research Unit we are indebted for statistical advice. To Dr. J. McFie and Mr. C. Jackson we are indebted for the psychological test reports.

\section{REFERENCES}

Ashby, W. R., and Bassett, M. (1950). J. ment. Sci., 96, 458.

Carscallen, H. B., Buck, C. W., and Hobbs, G. E. (1951). Arch. Neurol. Psychiat., Chicago, 65, 206.

Chapman, W. P., Rose, A. S., and Solomon, H. C. (1948). The Frontal Lobes, p. 754 . A.R.N.M.D. XXVII, Baltimore.

- - - - (1950). Amer. J. Psychiat., 107, 221.

Conklin, J. E. (1951). Amer. J. Psychol., 64, 78

Elithorn, A., Piercy. M. F., and Crosskey, M. A. (1950). Communication to Experimental Psychological Group. (Unpublished.)

- - , - - (1954a). Journal of Neurology, Neurosurgery and Psychiatry, 17, 139 .

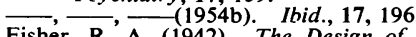

Fisher, R. A. (1942). The Design of Experiments, 3rd ed., p. 33 Oliver and Boyd. Edinburgh.

Hardy, J. D., Wolff, J. G., and Goodell, H. (1952). Pain Sensations and Reactions. Williams and Wilkins, Baltimore.

King, H. E., and Clausen, J. (1952). Psychosurgical Problems, p. 273, ed. Mettler, F. A. Routledge and Kegan Paul, London.

,--- , and Scarff, J. E. (1950). J. nerv. ment. Dis., 112, 93. Le Beau, J. (1950). J. Neurosurg., 7, 79.

Malmo, R. B., and Shagass, C. (1949). Psychosom. Med., 11, 25. , (1950). Arch. Neurol. Psychiat., Chicago, 63, 113.

. H. (1938). Psychol. Rev., 45, 62.

Solomon, H. C., and Greenblat, M. (1953). Res. Publ. Ass. nerv. ment. Dis., 31, 328.

Wolff, J. (1950)., Quoted by Freeman, W., and Watts, J. W. Psichosurgery, 2nd ed., p. 371 . Blackwell, Oxford.

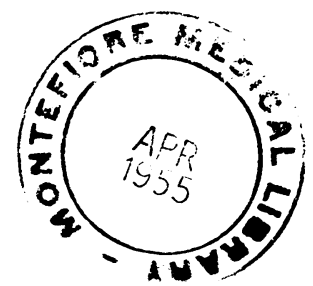

